\title{
Friction and Wear Properties of Nitrogen-doped graphene IUltrahigh-Molecular-Weight Polyethylene Composites
}

\author{
Jiatong Shi, a ${ }^{1}$, Longhua $\mathrm{Xu}^{1}$, Hengxi Cao ${ }^{2}$, Xingkai Zhang ${ }^{2}$, Bin Liu ${ }^{* 1, b}$ \\ ${ }^{1}$ School of stomatology, Lanzhou University, Lanzhou 730000, China \\ ${ }^{2}$ Lanzhou Institute of Chemical Physics, Chinese Academy of Science, Lanzhou 730000, China \\ a email: sjt566@163.com, bemail: liubkq@lzu.edu.cn
}

Keywords: UHMWPE; Nitrogen-doped graphene; Composite; Tribological properties

\begin{abstract}
Ultrahigh-molecular-weight polyethylene (UHMWPE) and nitrogen-doped graphene /Ultrahigh-molecular-weight polyethylene composite (NG/UHMWPE) samples were successfully fabricated through an optimized hot-pressing molding method. Friction and wear behavior of UHMWPE and NG/UHMWPE samples sliding against $\mathrm{ZrO}_{2}$ ceramic ball were investigated with a high-speed reciprocating friction tester. The mechanical property and wear volume of pure UHMWPE and NG/UHMWPE samples were characterized with micro-hardness tester and Micro-XAM 3D non-contact surface profiler. The worn morphology of pure UHMWPE and NG/UHMWPE samples were observed by scanning electron microscope (SEM). The results showed that, adding NG could not only improve the micro-hardness and wear resistance of UHMWPE and but also reduce the wear rate of UHMWPE significantly.
\end{abstract}

\section{Introduction}

Artificial joint replacement has become the main therapeutic method for osteoarthritis of hip and knee joint. The mechanical and biomedical properties of artificial joint material are crucial factors to promote the development of artificial joint replacement surgery [1] [2]. With the development of artificial joint replacement, postoperative complications ususlly occurs with the prolonged time of use, which causes operation failure. In these complications, the aseptic loosening of prosthesis commonly happenes. When the artificial joint functionating in the human body, a series of biochemical reactions was induced by the wear debris in vivo, which could lead to periprosthetic osteolysis and loosening of the prosthesis[3][4]. Therefore, the term survival of total joint replacements is dependent on the prevention of aseptic loosening. Ultra high molecular weight polyethylene (UHMWPE) is widely as artificial joint replacement materials for its good biological compatibility, stable physical and chemical properties, low friction, and high impact strength [5]. However, researchers have found that UHMWPE material of artificial joint implanted in the body begun to produce debris after used in body for 10-15 years, these debris induced periprosthetic osteolysis, resulting in aseptic loosening of the prosthesis[6] [7]. Therefore, the aim of our research is to modify the UHMWPE material, enhance its wear resistance and hardness and reduce the wear debris caused by the wear of the prosthesis in the joint cavity.

Nitrogen doped graphene(NG) is a kind of functional graphene with nitrogen functional groups, which has excellent physical and chemical properties, good mechanical properties, and optical properties[8]. In recently works, academics compared its cytocompatibility and hemocompatibility with pristine graphene, and the results indicated NG shows a better biocompatibility than pristine graphene [9]. At the same time, the study of mechanical properties of NG shows that, the stress-strain curve of NG analogous to many biological connective tissues, for example, articular cartilage, ligaments [10]. It also shows the good potential and advantages of NG which as an alternative biological material [11].

In our research, to explore the potential application of NG/UHMWPE composites as a material in the field of artificial joint, UHMWPE composites reinforced with NG were successfully fabricated through an optimized hot-pressing molding technology. 


\section{Experimental}

Materials. Powdered UHMWPE (M-II), Molecular weight was 2000000, purchased from Shanghai Lianle Chemical Technology Co., Ltd. Graphene oxide was purchased from Nanjing Xianfeng Nano Material Technology Co., Ltd. Zirconia ceramic ball (diameter $5 \mathrm{~mm}$, roughness $0.04 \mu \mathrm{m}$ ) was purchased from Shanghai Xinmaojing Ceramics Technology Co., Ltd. Analytically pure ethanol and melamine was purchased from Sinopharm Chemicals Co., Ltd.

Synthesis of Nitrogen-Doped Grapheme. A catalyst-free approach was used to synthesize NG by thermal annealing graphite oxide (GO) mixed with low-cost industrial material melamine. Annealing of GO was carried out in a tube furnace. High purity argon was used as protective ambient to anneal a mixture of GO and melamine (NG prepared with $\mathrm{GO} /$ melamine mass ratio of 1:5) [12].

Fabrication of the GO/UHMWPE Composites. Powdery NG and UHMWPE were firstly added into anhydrous ethanol. After ultrasonic treatment using an ultrasonic pole at $600 \mathrm{~W}$ for $1 \mathrm{~h}$, and then the homogeneous mixture was placed into a bottomed flask in an oil bath, heated up to $60{ }^{\circ} \mathrm{C}$, and kept at this temperature for $3 \mathrm{~h}$ under stirring. Then, the mixture was dried at $70{ }^{\circ} \mathrm{C}$ in vacuum for $12 \mathrm{~h}$ to get dried mixture. Finally, the mixture was hot pressed at $195{ }^{\circ} \mathrm{C}$ and $10 \mathrm{MPa}$ for $20 \mathrm{~min}$ to form NG/UHMWPE composites coupons with diameter of $22 \mathrm{~mm}$ and thickness of $1 \mathrm{~mm}$. NG/UNMWPE composite samples with the NG content of 0 wt. \%, 0.1 wt. \%, 0.3 wt. \%, 0.5 wt. \% and 1 wt. \% were prepared respectively.

Characterization. Worn morphology and microhardness of the NG/UNMWPE composite samples were characterized with scanning electron microscope (HR-SEM, JSM-6701) and microhardness detector (MH-5-VM, Shanghai Hengyi Precision Instrument Co., Ltd.). At least 15 spots were tested for each sample with the loading force of $10 \mathrm{~N}$, and took the average. Ball disc contacted UMT-3MT friction and wear tester was used to evaluation the friction and wear performance of NG/UNMWPE composite samples. It have been reported that zirconia ceramic materials can be widely used as the body of prosthesis materials for its lower friction coefficient, good biocompatibility, high mechanical strength and toughness. So zirconia ceramic ball was used as the couple. Friction test of each ample was carried out at least 3 times in the same test parameters: the loading force, test time, sliding speed, frequency and actual contact pressure of ceramic balls and samples are $5.0 \mathrm{~N}, 1 \mathrm{~h}, 10 \mathrm{~mm} / \mathrm{s}, 3 \mathrm{~Hz}$, and $6.56 \mathrm{MPa}$. The high-precision sensors of tester were used to detect the friction (F) and normal load force (L) in friction process. The coefficient of friction (COF) was calculated using the formula: $\mu=\mathrm{F} / \mathrm{L}$. After the friction tests, the wear rate (WR) was evaluated with a micro-XAM three-dimensional (3D) surface profiler and calculated as follows: $\mathrm{K}=\mathrm{V} / \mathrm{LD}$, where $\mathrm{K}$ is the wear rate; $\mathrm{V}$ is the volume of the amount of wear $\left(\mathrm{mm}^{3}\right)$; $\mathrm{L}$ is the applied normal load $(\mathrm{N})$; $\mathrm{D}$ is the total sliding distance $(\mathrm{m})$.

\section{Results and Discussions:}

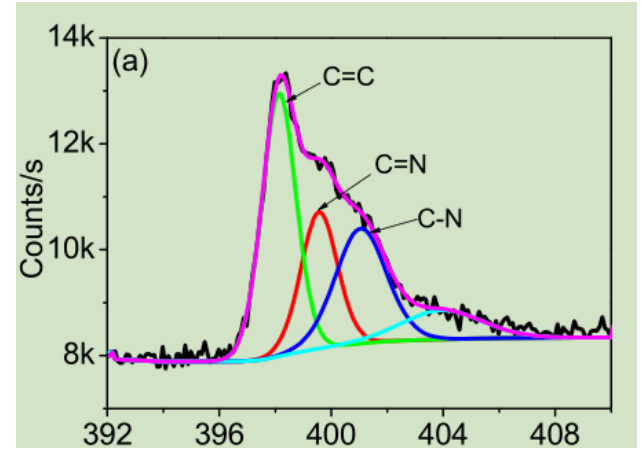

Fig. 1 N1s spectrum of nitrogen-doped graphene.

Fig. 1 shows the N1s spectrum of the NG, and it clearly presents the incorporation of nitrogen in the graphene sheets. The peak of $\mathrm{C}=\mathrm{N}$ and $\mathrm{C}-\mathrm{N}$ appeared after annealing process, and the $\mathrm{N}$ content in NG was about 8.39 atm. \%. 


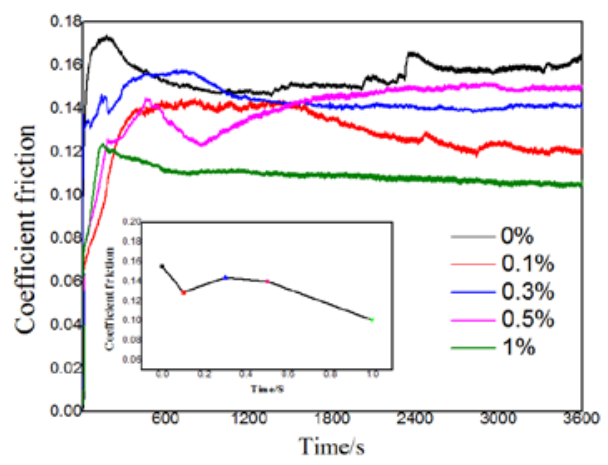

Fig. 2 Variations in the COF values of the NG/UHMWPE composite samples. The inset is the average COF values.

Friction coefficient and wear rate were usually used to evaluate the tribological properties of materials. Fig. 2 shows the variation of friction coefficient of different NG/UHMWPE composite samples during the wear tests. It can be seen that the friction coefficient of pure UHMWPE was about 0.100. Although the friction coefficient of the NG/UHMWPE composite samples increased slightly as compared to pure UHMWPE, both pure UHMWPE and NG/UHMWPE composite samples showed very low friction coefficients $(0.108-0.155)$. This trend was consistent with the previous research, where the friction coefficient was increased with the content of carbon nanotubes in the composites [13] [14]. The variations of friction coefficient of pure UHMWPE and NG/UHMWPE composite samples could be divided into two stages: the first eight hundred seconds is running-in period and the friction coefficient was not stable; and then the friction coefficient tended to be stable.
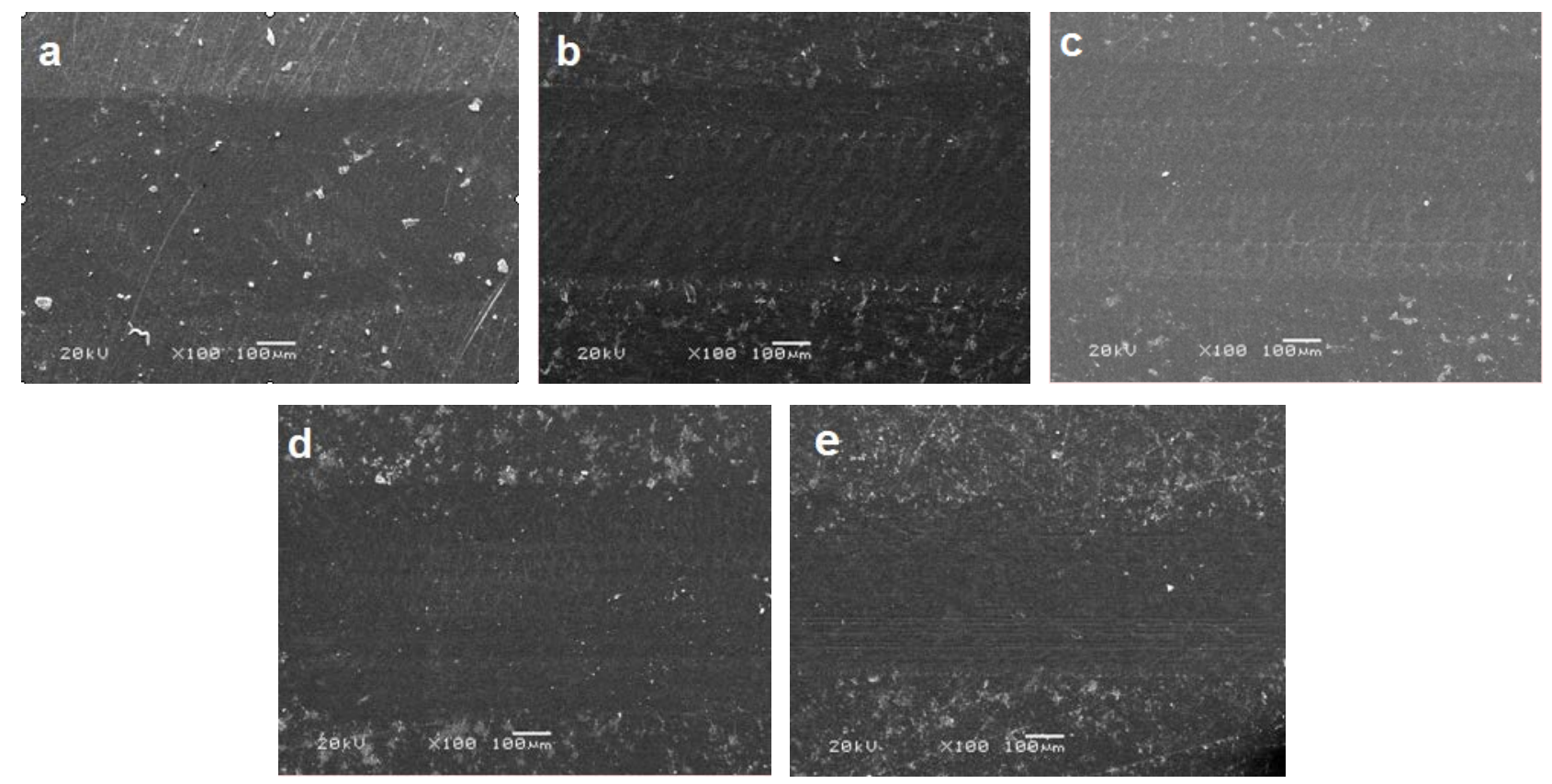

Fig. 3 SEM images of worn morphology of NG/UHMWPE composite samples with NG content of 0 wt. \% (a), 0.1 wt. \% (b), 0.3 wt. \% (c), 0.5 wt. \% (d) and 1 wt. \% (e).

Fig. 3 shows the worn morphology of different NG/UHMWPE composite samples. The wear of pure UHMWPE was quite serious, the main form of which is adhesion and abrasion. As NG was added, the wear of NG/UHMWPE composite samples decreased slowly with the increasing NG content. This was mainly because adding NG could improve the micro-hardness of UHMWPE. As the NG content is $1 \%$, the surface of the NG/UHMWPE composites gets smoother than the other samples. 


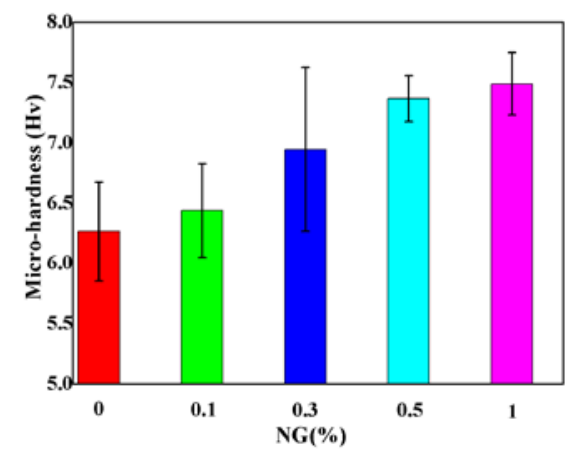

Fig. 4 The microhardness of NG/UHMWPE composite samples with the different NG contents

For artificial joint materials, hardness and creep resistance are the main factors that affect the working life. As is shown in Fig. 4, adding NG could lead to the increase of micro-hardness of UHMWPE composite samples. The micro-hardness of NG/UHMWPE composite samples was increased along with the NG content increase. The micro-hardness value could increase to its $115 \%$ when adding 1 wt. \% NG.

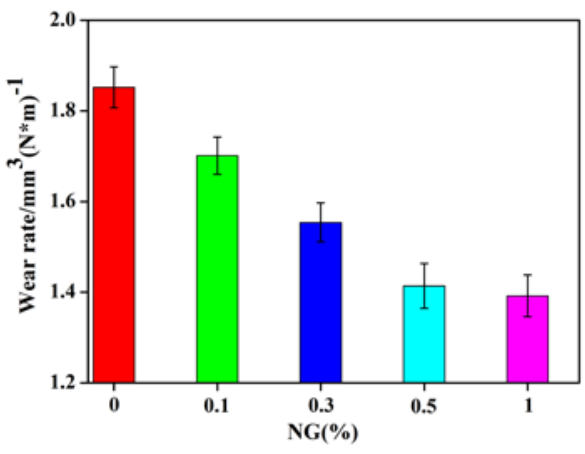

Fig. 5 Variations of WR of the NG/UHMWPE composite samples as a function of NG contents.

As is shown in Fig. 5, there was a tendency that the wear rate from the NG/UHMWPE composites decreased as the NG content increases. The wear rate of UHMWPE could be reduce to its 0.75 when the NG content is $1 \%$. Adding NG as nano-filler could obviously improve the wear resistance of UHMWPE matrix. The similar result was obtained from the other polymers using NG as a reinforce filler, where the wear rate also decreased with the increases of its content [13] [14].

\section{Conclusions}

Ultrahigh-molecular-weight polyethylene (UHMWPE) and nitrogen-doped graphene /Ultrahigh-molecular-weight polyethylene composite (NG/UHMWPE) samples were successfully fabricated through an optimized hot-pressing molding method. The results indicated both microhardness and wear resistance of the NG/UHMWPE composite samples increased along with the increase of NG content. As NG can improve the tribological behavior of UHMWPE, the NG/UHMWPE composites were expected to be a potential biomaterial in the field of artificial joint.

\section{Acknowledgement}

This research was sponsored by the National Natural Science Foundation of China (Project No. 51475447) 


\section{References}

[1] Perera J R, Gikas P D, Bentley G. The present state of treatments for articular cartilage defects in the knee[J]. Annals of the Royal College of Surgeons of England, 2012, 94(6): 381-387.

[2] Peel T N, Buising K L, Choong P F M. Prosthetic joint infection: challenges of diagnosis and treatment[J]. ANZ journal of surgery, 2011, 81(1 - 2): 32-39.

[3] Ushio K, Oka M, Hyon S H, et al. Attachment of artificial cartilage to underlying bone[J]. Journal of Biomedical Materials Research Part B: Applied Biomaterials, 2004, 68(1): 59-68.

[4] Stea S, Visentin M, Granchi D, et al. Cytokines and osteolysis around total hip prostheses[J]. Cytokine, 2000, 12(10): 1575-1579.

[5] Li S, Burstein A H. Ultra-high molecular weight polyethylene. The material and its use in total joint implants[J]. The Journal of Bone \& Joint Surgery, 1994, 76(7): 1080-1090.

[6] Essner A, Polineni V K, Schmidig G, et al. Long-term wear simulation of stabilized UHMWPE acetabular cups[J]. Trans 43rd Orthop Res Soc, 1997, 22: 784.

[7] Cho H J, Wei W J, Kao H C, et al. Wear behavior of UHMWPE sliding on artificial hip arthroplasty materials[J]. Materials chemistry and physics, 2004, 88(1): 9-16.

[8] Mohanty N, Berry V. Graphene-based single-bacterium resolution biodevice and DNA transistor: interfacing graphene derivatives with nanoscale and microscale biocomponents[J]. Nano letters, 2008, 8(12): 4469-4476.

[9] Guo M, Li D, Zhao M, et al. Nitrogen ion implanted graphene as thrombo-protective safer and cytoprotective alternative for biomedical applications[J]. Carbon, 2013, 61: 321-328.

[10] Shan C, Zhao W, Lu X L, et al. Three-dimensional nitrogen-doped multiwall carbon nanotube sponges with tunable properties[J]. Nano letters, 2013, 13(11): 5514-5520.

[11] Vardharajula S, Ali S Z, Tiwari P M, et al. Functionalized carbon nanotubes: biomedical applications[J]. International journal of nanomedicine, 2012, 7: 5361-5374.

[12] Sheng Z H, Shao L, Chen J J, et al. Catalyst-free synthesis of nitrogen-doped graphene via thermal annealing graphite oxide with melamine and its excellent electrocatalysis[J]. ACS nano, 2011, 5(6): 4350-4358.

[13] Burris D L, Boesl B, Bourne G R, et al. Polymeric nanocomposites for tribological applications[J]. Macromolecular materials and engineering, 2007, 292(4): 387-402.

[14] Zoo Y S, An J W, Lim D P, et al. Effect of carbon nanotube addition on tribological behavior of UHMWPE[J]. Tribology Letters, 2004, 16(4): 305-309. 